\title{
Visualisation of Uncertainty in 30m Resolution Global Digital Elevation Models: SRTM v3.0 and ASTER v2
}

\author{
J. O. Olusina ${ }^{*}$, C. J. Okolie
}

Department of Surveying and Geoinformatics, Faculty of Engineering, University of Lagos, Lagos State, Nigeria.

\begin{abstract}
Geospatial visualisation presents us with innovative techniques of assessing uncertainty in digital elevation datasets. It gives the viewer immediate feedback on potential problems and heightens understanding of effects not easily appreciated when dealing with numerical statistics only. This study evaluated the performance of 30-metre resolution SRTM version 3.0 and ASTER GDEM version 2 over Lagos, Nigeria. Both datasets were examined by direct comparison with 176 highly accurate Ground Control Points (GCPs) coordinated by GPS (Global Positioning System) observation. The basis of comparison was on the elevation differences between the Digital Elevation Models (DEMs) and the GCPs at coincident points. The performance of both DEMs was visualised in $2 \mathrm{D}$ and $3 \mathrm{D}$ space by comparing pixel values and surface models. In the assessment, the absolute vertical accuracies of SRTM v3.0 and ASTER v2 are $4.23 \mathrm{~m}$ and $28.73 \mathrm{~m}$ respectively. The accuracy of SRTM for the study site proved to be higher than the value of $16 \mathrm{~m}$ presented in the original SRTM requirement specification. ASTER did not meet up with its $17 \mathrm{~m}$ overall accuracy specification.
\end{abstract}

KEYWORDS: Uncertainty, Visualisation, Digital Elevation Model, SRTM, ASTER.

[Received April 15 2017; Revised March 24 2018; Accepted March 24 2018]

Print ISSN: 0189-9546 | Online ISSN: 2437-2110

\section{INTRODUCTION}

Digital elevation models (DEMs) are fundamental spatial data infrastructure that supports a wide range of applications in environmental modelling (Nwilo et al., 2012). A DEM is defined as "an ordered or unordered digital set of ground elevations (spot heights) for terrain representation" (Zhou, 2017). Today, there are several satellite-derived DEM products with global coverage available to the global user community. Although the process of DEM construction is quite rigorous, the products are still known to contain attribute errors (wrong elevation values) (Temme et al., 2009).

These attribute errors in DEMs may be displayed by a number of visualisation techniques such as rendering the DEM with a shaded-relief map; overlaying colours/textures to represent the magnitude of various quantified errors; and adding special glyphs to indicate additional information such as direction (Gousie and Smith, 2010). To quantitatively ascertain the attribute errors, a standard uncertainty measure such as the Root Mean Square Error (RMSE) can be computed (Rinehart and Coleman, 1988). Elevations obtained by highly accurate Differential Global Positioning System (DGPS) survey are commonly used to validate DEM accuracy (e.g. Rexer and Hirt, 2014; Patel et al., 2016).

The Shuttle Radar Topography Mission DEM (SRTM) was co-sponsored by the National Aeronautics and Space Administration (NASA) and the National Geospatial-
Intelligence Agency (NGA) of the United States of America (Dowding et al., 2004). SRTM used a radar interferometer (Rodriguez and Martin, 1992; Rosen et al., 2000) to generate a globally consistent digital elevation map for latitudes lower than $60^{\circ}$. The guidelines of the SRTM mission specified an accuracy requirement of $16 \mathrm{~m}$ absolute vertical error $(90 \%$ linear error) (Karwel and Ewiak, 2008). SRTM v3.0 is a 30metre enhancement to an initial SRTM 90-metre dataset.

Before the release of version 3.0, the best available $90 \mathrm{~m}$ SRTM DEMs for regions outside the United States were: (i) SRTM v3 released by NASA in November 2013 (NASA LP DAAC, 2013), and (ii) SRTM v4.1 released by the Consultative Group for International Agricultural Research Consortium for Spatial Information (CGIAR-CSI) in 2008 (Jarvis et al., 2008). The Advanced Spaceborne Thermal Emission and Reflection Radiometer (ASTER) Global DEM (GDEM) is a product of collaboration between the US National Aeronautics and Space Administration (NASA) and the Ministry of Economy, Trade and Industry (METI) of Japan.

Two versions of ASTER have so far been released ASTER v1 (GDEM1) and ASTER v2 (GDEM2). In 2011, GDEM2 was released with several improvements over GDEM1 such as the use of additional scenes to improve coverage, a smaller correlation kernel to yield higher spatial resolution, and an improved water mask (NASA/METI, 2011). Assessments by the ASTER GDEM Validation Team 
(2011) showed that GDEM2 was within -0.20 meters on average when compared against 18,000 geodetic control points over the Conterminous United States (CONUS), with an accuracy of $17 \mathrm{~m}$ at the $95 \%$ confidence level.

On accuracy assessment of SRTM and ASTER DEMs, several studies have compared the performance of both products at study sites all around the world. For example, Rexer and Hirt (2014) compared and evaluated ASTER GDEM v2, SRTM3 USGS v2.1 and CGIAR-CSI SRTM v4.1 over the Australian continent. The RMSE obtained from the differences between ASTER GDEM2 and SRTM was found to be around $9.5 \mathrm{~m}$. An external validation of the models with over 228,000 accurate station heights from the Australian National Gravity Database yielded the following elevation accuracies: ASTER GDEM2 $\sim 8.5 \mathrm{~m}$, SRTM3 USGS $\sim 6 \mathrm{~m}$, and SRTM CGIAR-CSI $\sim 4.5 \mathrm{~m}$ (RMSE). Isioye and Yang (2013) investigated the quality of CGIAR-CSI SRTM v4.1 and ASTER v1 (GDEM1) in the mountainous region of Kajuru/Kaduna and in the flat terrain of Zaria both in Northern Nigeria.

The results showed that GDEM1 was slightly better correlated in the mountainous terrain while SRTM showed a significantly stronger correlation in the flat terrain. The overall absolute average vertical errors for the sites was Kajuru/Kaduna (GDEM1: $18.93 \pm 2.85 \mathrm{~m}$; SRTM: $12.52 \pm$ $3.25 \mathrm{~m})$ and Zaria (GDEM1: $16.36 \pm 2.14 \mathrm{~m}$; SRTM: $3.17 \pm$ $1.17 \mathrm{~m})$. In a more recent effort, Menegbo and Doosu (2015) compared the vertical accuracy of SRTM3 v2.1 and ASTER GDEM2 with reference to GPS control points. The study showed the RMSE for GDEM2 and SRTM3 v2.1 to be \pm $8.862 \mathrm{~m}$ and $\pm 6.307 \mathrm{~m}$, with vertical accuracy of $\pm 17.362 \mathrm{~m}$ and $\pm 12.362 \mathrm{~m}$ respectively.

From the foregoing, it is evident that the accuracies of DEMs vary from one location to another and is also terrain dependent. It is therefore important to conduct localised assessments of these products in different regions of the world. This study presents a performance assessment of the SRTM v3.0 and ASTER v2 Global DEMs over the relatively flat and low relief area of Lagos, Nigeria through visualisation of uncertainty magnitudes in $2 \mathrm{D}$ and $3 \mathrm{D}$ space. It informs the global user community on a novel procedure for performance assessment of satellite-derived DEMs.

\section{METHODOLOGY}

A. Study Area

The study area is a section of Lagos State that lies between Latitudes $6^{\circ} 20^{\prime} 00^{\prime \prime}-6^{\circ} 45^{\prime} 20^{\prime \prime} \mathrm{N}$ and Longitudes $3^{\circ} 00^{\prime} 30^{\prime \prime}-3^{\circ} 37^{\prime} 30^{\prime \prime}$ E. Lagos is a low-lying coastal State and is Nigeria's centre of commerce. The state has a very diverse and fast-growing population, resulting from heavy and ongoing migration to its cities from all parts of Nigeria as well as neighbouring countries. Lagos was the capital city of the country before it was moved to Abuja on 12th December, 1991. The land surface in the state generally slopes gently downwards from north to south, and is naturally made up of depositional landforms which include: wetlands, barrier islands, beaches, low-lying tidal flats and estuaries (Iwugo et al., 2003). Figure 1 shows a map of the study area.

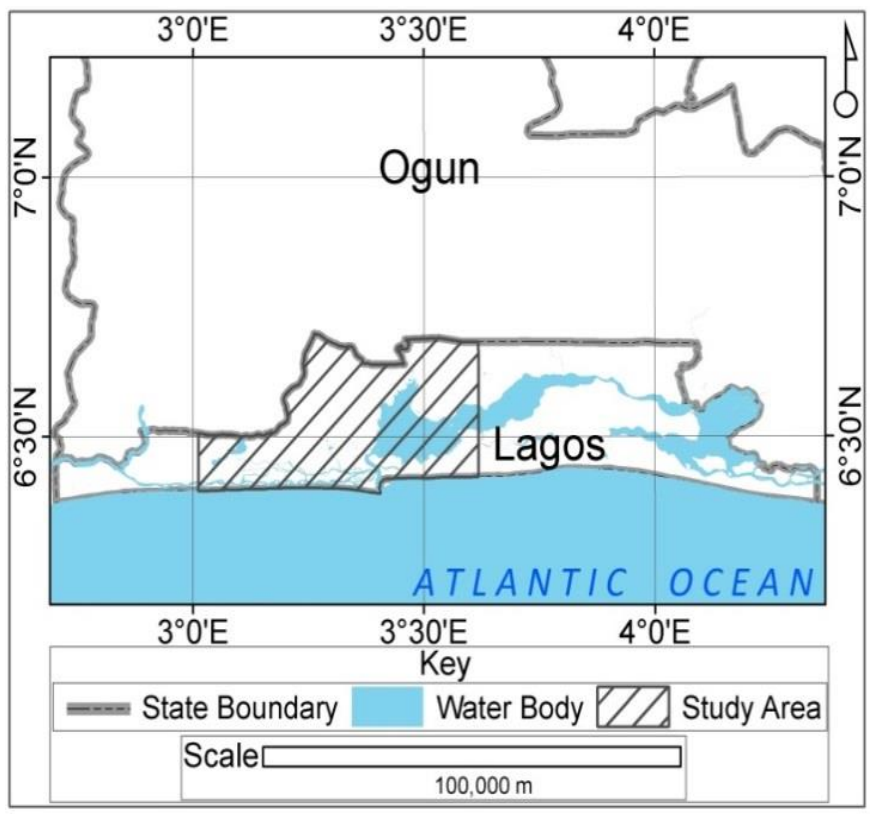

Figure 1: Map of the study area (Source: Author, 2017)

\section{B. Data Acquisition}

SRTM v3.0 and ASTER v2 elevation datasets were downloaded from the USGS (United States Geological Surveys) EarthExplorer online portal (https://earthexplorer.usgs.gov/). Both DEMs are provided in $1^{\circ} \mathrm{x} 1^{\circ}$ tiles at 1 arc-second $(30 \mathrm{~m})$ resolution and are on WGS84 datum. Also, both are referenced to mean sea level realised by the EGM 96 geoid model. Hence, the heights are orthometric with vertical units in metres. 176 first and second order GPS control points with geodetic coordinates (latitude $\varphi$, longitude $-\lambda$, height $-\mathrm{H}$ ) and on WGS84 datum were acquired from Interspatial Technologies Limited. These GPS control points were established by Interspatial during the Lagos State Geographic Information System and Digital Mapping Project which started in 2008. The GPS points were supplied with both ellipsoidal and corresponding orthometric heights. Thus orthometric heights are available for the three (3) datasets. More characteristics of the DEMs are summarised in Table 1.

Table 1: DEM datasets and characteristics.

\begin{tabular}{|c|c|c|c|}
\hline Dataset & $\begin{array}{l}\text { Coordinate } \\
\text { System }\end{array}$ & $\begin{array}{c}\text { Geoid } \\
\text { Reference }\end{array}$ & Resolution \\
\hline $\begin{array}{l}\text { SRTM v3.0 } \\
\text { ASTER v2 }\end{array}$ & $\begin{array}{l}\text { Geodetic } \\
(\varphi, \lambda, H) \\
\text { WGS } 84\end{array}$ & $\begin{array}{l}\text { WGS84/ } \\
\text { EGM96 }\end{array}$ & $\begin{array}{l}1 \text { arc-second } \\
(30 \mathrm{~m})\end{array}$ \\
\hline
\end{tabular}

\section{Processing Steps}

The data processing follows four stages:

1. Datum harmonisation

2. Extraction of coincident elevation points

3. Computation of accuracy parameters, and

4. Visualisation of height differences.

In the datum harmonisation, the DEMs were re-projected from a geographic coordinate system to the Universal Transverse Mercator (UTM) grid system on ArcGIS 10.1. This transformation helped to overcome linear measurement 
difficulties and preserve geometric properties of the DEMs. Next, the GPS points were overlaid on the DEMs on ArcGIS and with the 'extract values to points' tool, elevations were extracted from the DEMs at points coincident with the GPS data. The DEM point elevations were then subtracted from the GPS point elevations and the differences were tabulated and subsequently plotted in Surfer 11 using Inverse Distance Weighted (IDW) interpolation to produce 3-dimensional views. The elevation differences were used to compute the following parameters on Microsoft Excel 2010: Standard Deviation (S.D) and the Root Mean Square Error (RMSE).

The RMSE is a widely adopted parameter in describing the attribute accuracy of DEMs. In this study, the RMSE describes the absolute vertical accuracy of the DEMs under study. In a further step, the DEM points were plotted against the GPS points and fitted with $95 \%$ confidence bounds using Matlab 2016. In the visualisation, contours interpolated from the GPS points on GlobalMapper 15 were overlaid on the DEMs for a gridwise comparison at a test site in Festac Town, Lagos. The capability of the DEMs to mask areas covered by water bodies was also tested in a section of the Lagos Lagoon.

\section{RESULTS AND DISCUSSION}

\section{A. Analysis of DEM Accuracy}

The descriptive statistics of elevation values of the compared points $\left(\mathrm{H}_{\mathrm{SRTM}}, \mathrm{H}_{\mathrm{ASTER}}\right.$ and $\left.\mathrm{H}_{\mathrm{GPS}}\right)$ and the vertical differences between limits $\left(\Delta \mathrm{H}_{\text {SRTM-GPS }}\right.$ and $\left.\Delta \mathrm{H}_{\text {ASTER-GPS }}\right)$ are shown in Tables 2 and 3 respectively. The minimum elevation for the GCPs is $1.0 \mathrm{~m}$ while the maximum is $66.8 \mathrm{~m}$. A comparison of coincident points from both DEMs with the reference GPS points shows that this height difference varies spatially. The coincident points from the SRTM and ASTER have the following minimum and maximum values (SRTM: min $-0 \mathrm{~m}$, $\max -67 \mathrm{~m}$; ASTER: $\min -1 \mathrm{~m}$, $\max -152 \mathrm{~m})$. The highest discrepancy between SRTM and the GPS points is $36.4 \mathrm{~m}$; between ASTER and the GPS points, it is $149.7 \mathrm{~m}$.

For SRTM, 22.7\% of the points underestimated the GPS elevations while $77.3 \%$ overestimated the GPS elevations. For the ASTER points, the underestimations were $8 \%$ and the overestimations were $92 \%$. The RMSE of SRTM and ASTER over the study area were computed as $4.23 \mathrm{~m}$ and $28.73 \mathrm{~m}$ respectively.

Table 2: Descriptive statistics of the elevation points under comparison.

\begin{tabular}{lccc}
\hline \multicolumn{1}{c}{ Parameter } & $\mathrm{H}_{\text {SRTM }}(\mathrm{m})$ & $\mathrm{H}_{\mathrm{ASTER}}(\mathrm{m})$ & $\mathrm{H}_{\mathrm{GPS}}(\mathrm{m})$ \\
\hline Min & 0 & 1 & 1 \\
Max & 67 & 152 & 66.8 \\
Range & 67 & 151 & 65.8 \\
Mean & 17.1 & 37 & 15.3 \\
$\mathrm{R}^{2}$ & 0.94 & 0.48 & - \\
\hline
\end{tabular}

Table 3: Descriptive statistics of the difference in vertical distance between limits.

\begin{tabular}{lcc}
\hline Parameter & $\Delta \mathrm{H}_{\text {SRTM-GPS }}(\mathrm{m})$ & $\Delta \mathrm{H}_{\text {ASTER-GPS }}(\mathrm{m})$ \\
\hline Min* & 0.0 & 1.1 \\
Max* & 36.4 & 149.7 \\
Range & 36.4 & 148.6 \\
Mean & 1.8 & 21.7 \\
S.D & 3.8 & 18.9 \\
RMSE & 4.23 & 28.73 \\
\hline
\end{tabular}

*Absolute value

The errors in SRTM are generally of a minor amplitude when compared to that of ASTER. Figures 2 and 3 display scatter plots of the GPS points versus the SRTM and ASTER DEMs respectively fitted with $95 \%$ confidence bounds above with the residuals plot shown below. The R-square values $\left(\mathrm{R}^{2}:\right.$ SRTM $=0.94$, ASTER $\left.=0.48\right)$ show a high level of agreement between the SRTM data and the reference GPS points and a not too good agreement between the ASTER and GPS points. The highest residual observed in SRTM is $36.4 \mathrm{~m}$ while the highest residual in ASTER is $149.7 \mathrm{~m}$.

A greater percentage of the residuals in both SRTM and ASTER occur in low-lying areas ranging from 0 to $10 \mathrm{~m}$. This can be attributed to the fact that these low-lying areas are some of the most densely populated regions with a lot of landscape obstructions such as buildings and above-ground vegetal cover. These landscape obstructions block the satellite pulses from reaching the ground and in effect mask the true terrain height.

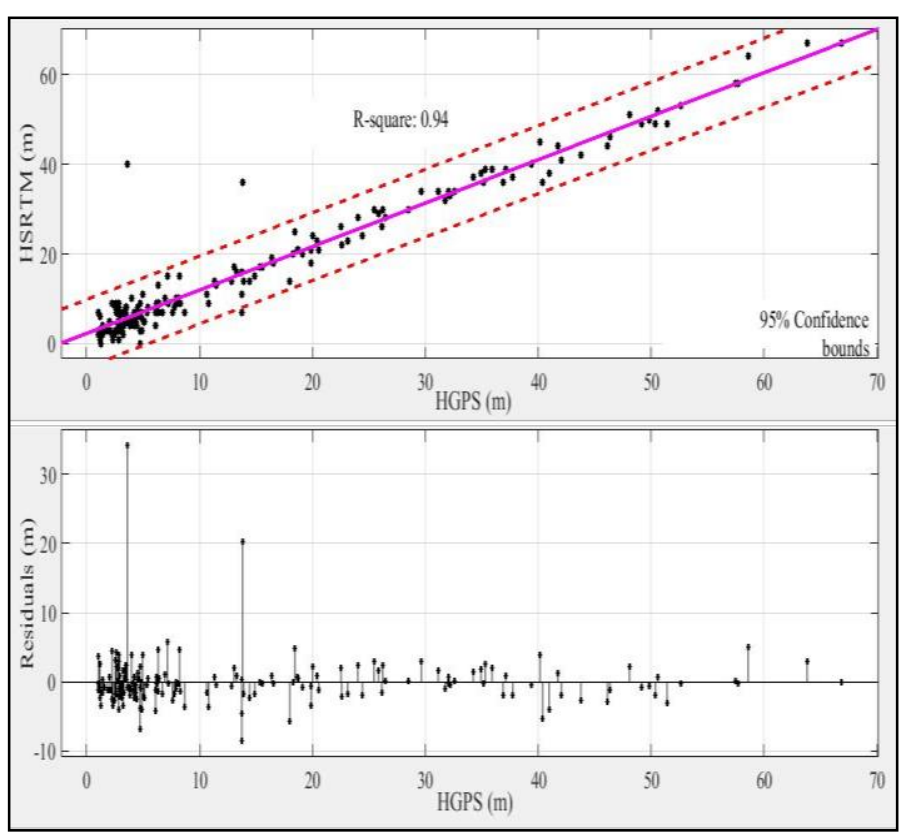

Figure 2: Visual comparison of $\mathbf{H}_{\mathrm{SRTM}}$ vs. $\mathrm{H}_{\mathrm{GPS}}$ : expression of $95 \%$ confidence zone (above) and residuals plot (below). 


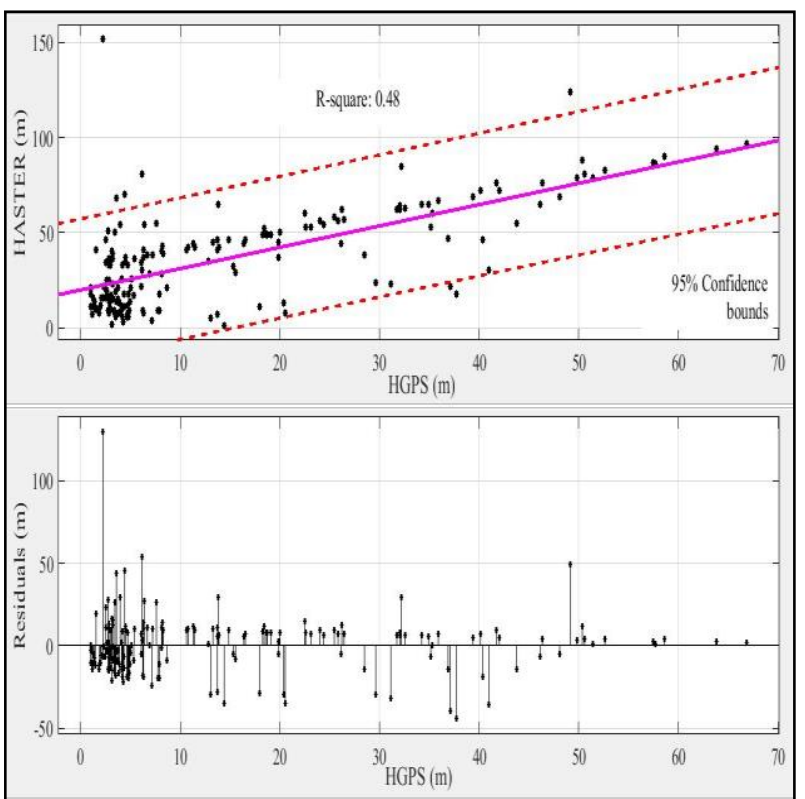

Figure 3: Visual comparison of $\mathbf{H}_{\mathrm{ASTER}}$ vs. $\mathrm{H}_{\mathrm{GPS}}$ : expression of $95 \%$ confidence zone (above) and residuals plot (below).

\section{B. Comparison of DEM Attributes}

A comparison of SRTM and ASTER pixel values in a section of Festac Town, Lagos against a GPS elevation contour $\left(\mathrm{H}_{\mathrm{GPS}}\right)$ with value of $3.5 \mathrm{~m}$ is shown in Figures 4 and 5 respectively. A DEM of good quality should have (almost) the same values as contours when close to contour lines; the DEM values must be in the range given by the bounding contour lines; and the values should vary almost linearly between the values of the bounding contour lines (Carrara $e t$ al., 1997 in Temme et al., 2009). In this close-up comparison, SRTM overestimated the GPS heights by no more than $8 \mathrm{~m}$. ASTER manifests very high differences in many areas with elevations being overestimated by over $300 \mathrm{~m}$ at certain points. With its substantial attribute errors, ASTER does not reflect realistic morphology in the area and its values are far out of range of the contour value.

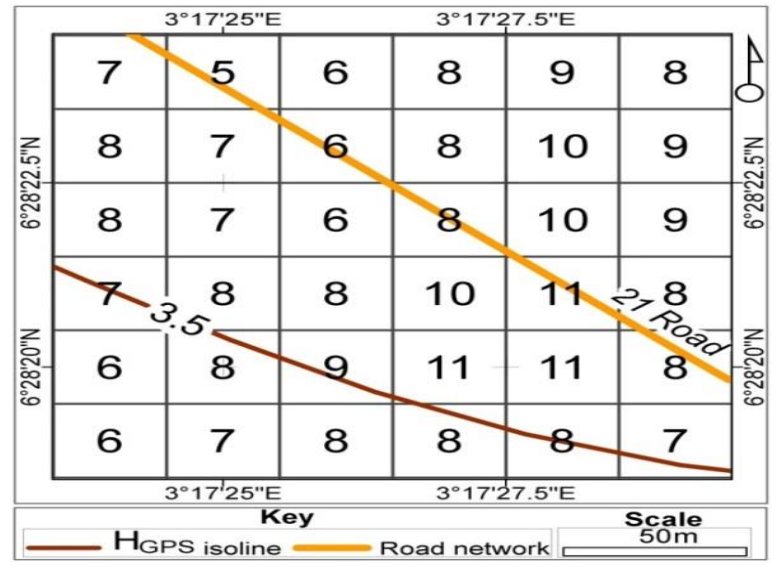

Figure 4: SRTM pixel values compared with a $\mathbf{H}_{\text {GPS }}$ contou at Festac town, Lagos.

\begin{tabular}{|c|c|c|c|c|c|c|c|}
\hline & & $3^{\circ} 17: 25 " \mathrm{E}$ & & $3^{\circ} 17^{\prime \prime}$ & $7.5^{\prime \prime} \mathrm{E}$ & & \\
\hline & 328 & 323 & 334 & 347 & 349 & 352 & P \\
\hline$\sum_{i=0}$ & 309 & 323 & 336 & 346 & 349 & 356 & \\
\hline జ్ & 298 & 321 & 340 & - & 346 & 344 & ฮิ \\
\hline & $2 \times 8$ & 305 & 327 & 333 & 335 & 341 & \\
\hline 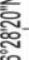 & 261 & 289 & 319 & 330 & 331 & 31 & \\
\hline & 256 & 273 & 306 & 326 & 328 & 321 & \\
\hline & & & & $3^{\circ} 17$ & 7.5"E & $\begin{array}{l}\text { Scale } \\
\text { 501 }\end{array}$ & \\
\hline
\end{tabular}

Figure 5: ASTER pixel values compared with a $\mathbf{H}_{\text {GPS }}$ contour at Festac Town, Lagos.

The elevation over the water surface in a section of the Lagos Lagoon was compared for the two DEMs to see how well the DEM production system masked the water surface. On the SRTM surface shown in Figure 6, the lagoon has a uniform level at $0 \mathrm{~m}$. However, the result for ASTER shown in Figure 7 reveals a non-level water surface. On the representation of these water surface elevations, SRTM has been shown to benefit from a uniform water level (0m) over water bodies. NASA/METI (2011) reported that the ASTER GDEM2 has an improved water mask and more realistic values over water bodies. Results in this study however show the values for ASTER over the Lagos Lagoon site are far from realistic. With this non-level surface, ASTER will require a great deal of terrain preprocessing to level out such water bodies before it can be used for certain hydrological applications.

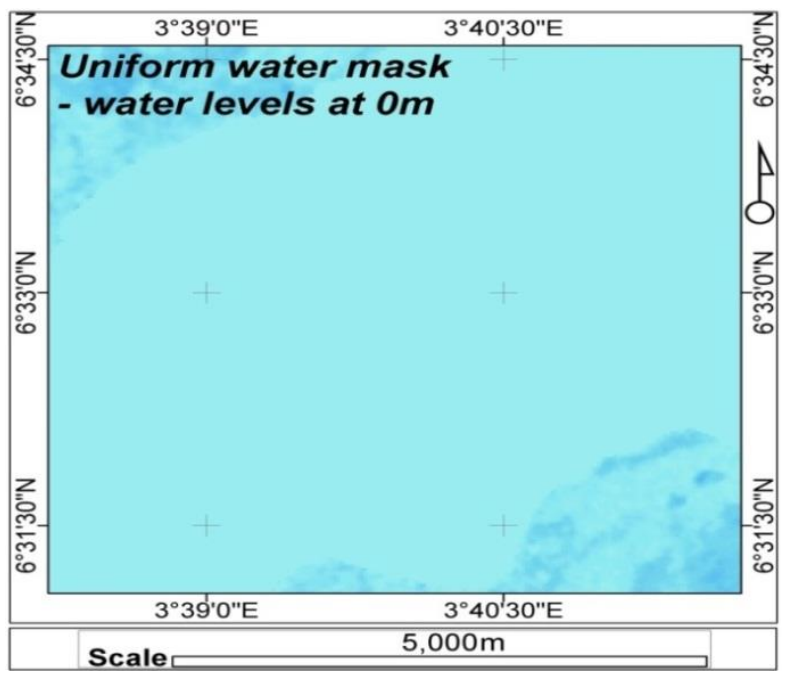

Figure 6: Evaluation of SRTM water masking in a section of the Lagos Lagoon. 


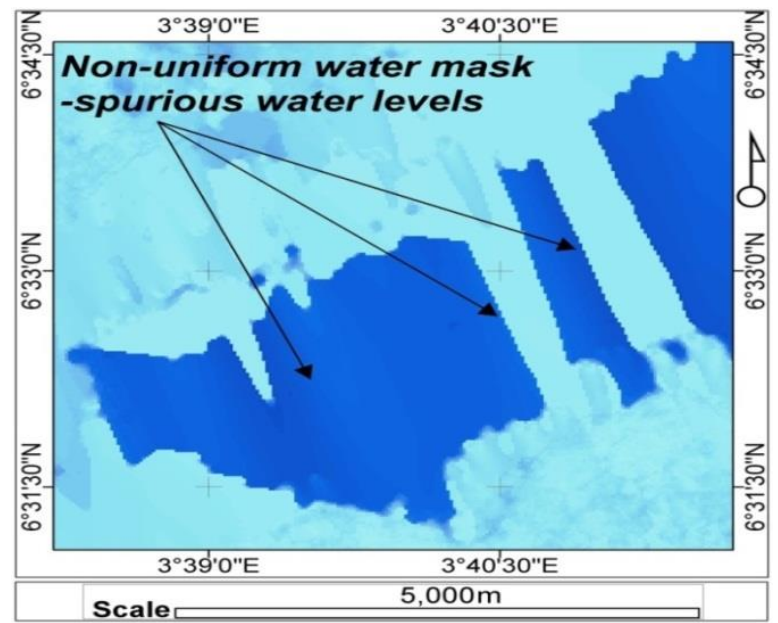

Figure 7: Evaluation of ASTER water masking in a section of the Lagos Lagoon.

\section{Visualisation of Height Differences}

The discrepancies in the elevation $\left(\Delta \mathrm{H}_{\mathrm{SRTM} \text {-GPS }}\right.$ and $\left.\Delta \mathrm{H}_{\mathrm{ASTER}-\mathrm{GPS}}\right)$ are represented as $3 \mathrm{D}$ surface models in Figures 8 and 9 respectively. For $\Delta \mathrm{H}_{\mathrm{SRTM}-\mathrm{GPS}}$ and $\Delta \mathrm{H}_{\mathrm{ASTER}-\mathrm{GPS} \text {, the }}$ mean error values are $1.8 \mathrm{~m}$ and $21.7 \mathrm{~m}$ respectively. The discordant terrain characterisation caused by high amplitude errors in ASTER is very observable. Conversely, the SRTM error surface shows more conformity with the reference terrain from GPS. The most noticeable spikes in both datasets are: SRTM $(67 \mathrm{~m}, 64 \mathrm{~m})$ and ASTER $(152 \mathrm{~m}, 124 \mathrm{~m})$. A close visualisation of both DEMs shows the presence of artefacts and spikes in some areas. These effects are more pronounced in the ASTER DEM. This non-homogeneity in the surface characterisation can be partly attributed to the influence of landscape obstructions which produce misrepresentations in elevations.

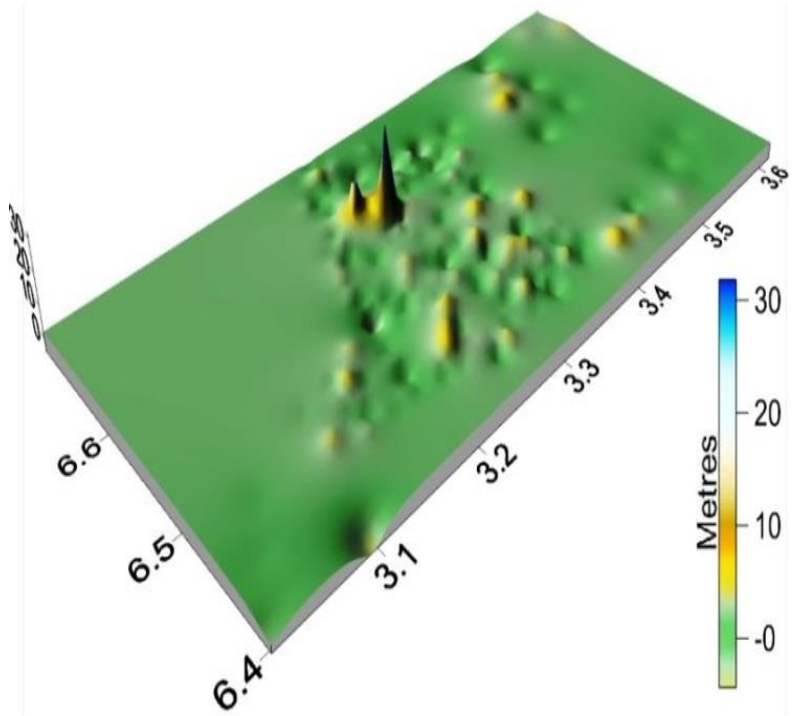

Figure 8: 3D model showing magnitude of errors in SRTM ( $\left.\Delta \mathrm{H}_{\text {SRTM-GPS }}\right)$.

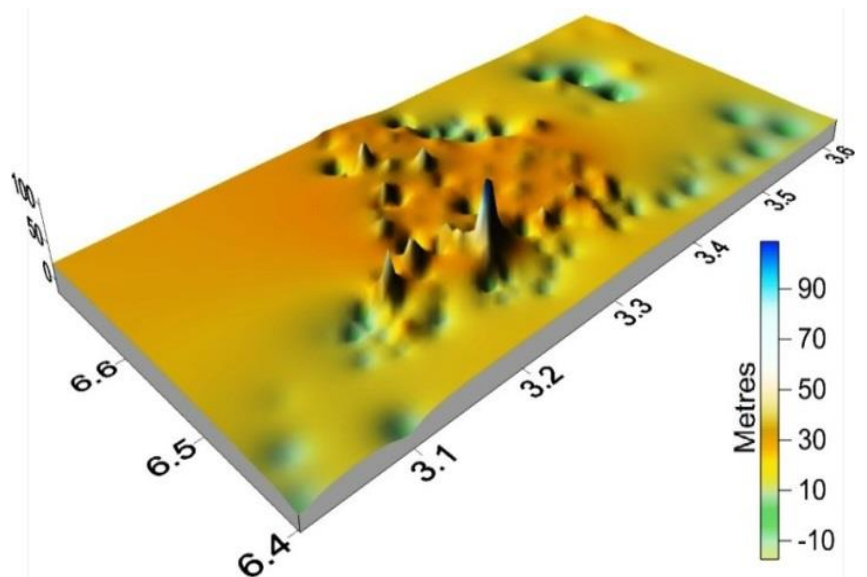

Figure 9: 3D model showing magnitude of errors in $\operatorname{ASTER}\left(\Delta \mathbf{H}_{\text {ASTER-GPS }}\right)$.

Figures 10 and 11 show 2-dimensional visualisations of the SRTM and ASTER error surface models. In Table 4, a grouping of these error magnitudes into classes of equal intervals is presented. From the table, it can be seen that $68.75 \%$ of the sampled points from SRTM have errors ranging from 0 to $5 \mathrm{~m}$. Conversely, only $6.82 \%$ of the sampled points from ASTER fall within this range. A greater percentage of the ASTER points (52.84\%) have linear vertical errors greater than $20 \mathrm{~m}$. Figure 11 shows that these points are concentrated in the centre of the Lagos metropolitan area. In effect, the errors in ASTER are of such a great magnitude that it limits the scope of its applications in environmental modelling.

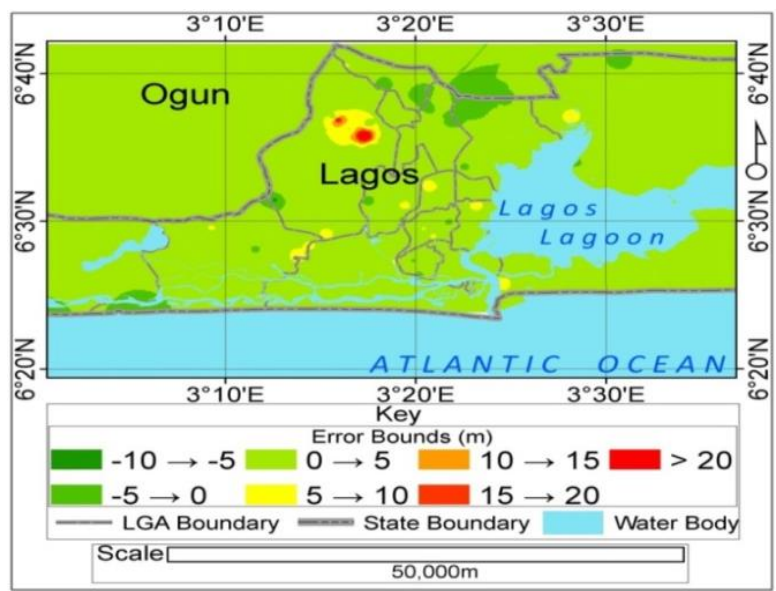

Figure 10: Surface model of $\Delta H_{\text {SRTM-GPS }}$ showing error bounds. 


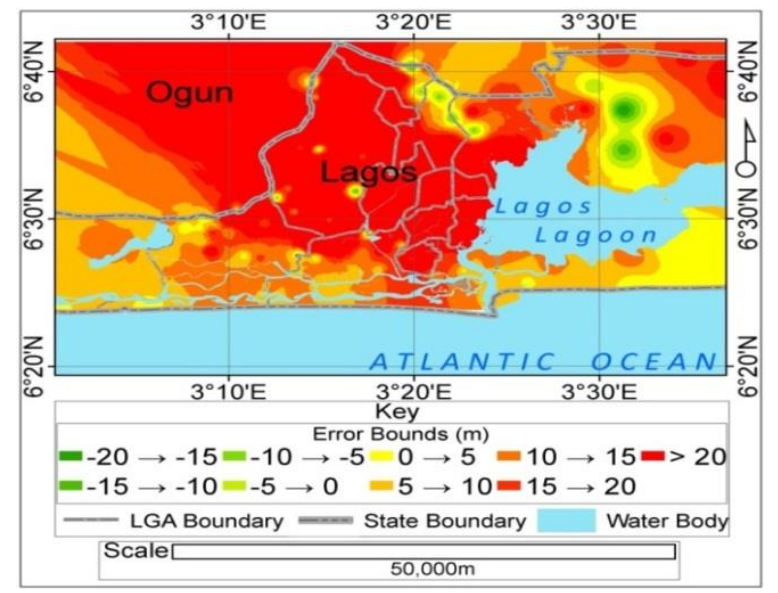

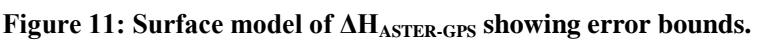

Table 4: SRTM and ASTER error magnitudes categorised by Percentages into error bounds.

\begin{tabular}{ccc}
\hline Error Bounds $(\mathbf{m})$ & \multicolumn{2}{c}{ Percentage (\%) } \\
& H $_{\text {SRTM }}(\mathbf{m})$ & $\mathbf{H}_{\text {ASTER }}(\mathbf{m})$ \\
\hline$-20 \rightarrow-16$ & Nil & 1.14 \\
$-15 \rightarrow-11$ & Nil & 1.70 \\
$-10 \rightarrow-6$ & 0.57 & 3.41 \\
$-5 \rightarrow 0$ & 22.16 & 1.70 \\
$0 \rightarrow 5$ & 68.75 & 6.82 \\
$6 \rightarrow 10$ & 7.39 & 14.20 \\
$11 \rightarrow 15$ & 0.00 & 10.80 \\
$16 \rightarrow 20$ & 0.00 & 7.39 \\
$>20$ & 1.14 & 52.84 \\
Total & 100 & 100 \\
\hline
\end{tabular}

\section{CONCLUSION}

The mean differences of SRTM and ASTER show that satellite-derived elevation data tend to overestimate the actual ground elevation. The absolute vertical accuracy for SRTM v3.0 of $4.23 \mathrm{~m}$ in this study far surpasses the $16 \mathrm{~m}$ accuracy requirement presented in the original SRTM specification while that of ASTER GDEM2 study $(28.73 \mathrm{~m})$ falls below the overall accuracy of $17 \mathrm{~m}$ at the $95 \%$ confidence level given by NASA/METI (2011). The results indicate the GDEM2 is of little use in areas with low relief and flat terrain. SRTM v3.0 has a higher level of dependency and is superior to the GDEM2 over the study area. GDEM2 still requires more filtering and improvement to reach the quality level of the SRTM.

However, it can still be regarded as a fairly good database over regions that are not covered fully by SRTM. The superior performance of SRTM over ASTER especially in flat terrain similar to the study area is in consonance with results from earlier findings in the existing literature. This study concludes that SRTM v3.0 is highly suitable for deployment in low-lying areas with relatively flat terrain while ASTER GDEM2 still remains a research-grade product in such areas. Further research can probe the nature of error transference from the DEMs to their terrain derivatives such as slope and aspect.

\section{REFERENCES}

ASTER GDEM Validation Team (2011). ASTER Global Digital Elevation Model Version 2 - Summary of Validation Results. August 31, 2011.

Carrara A.; G. Bitelli; and R. Carla (1997). Comparison of Techniques for Generating Digital Terrain Models from Contour Lines. International Journal of Geographical Information Science. 11(5), 451-473.

Dowding, S.; T. Kuuskivi; and X. Li (2004). Void fill of SRTM Elevation Data-Principles, Processes and Performance. Proceedings of the Conference "ASPRS Images to Decision: Remote Sensing Foundation for GIS Applications", Kansas City, MO, September 12-16.

Gousie, M.B. and Smith, M.J. (2010). DEMView: 3D Visualisation of DEM Error. In Accuracy 2010, Proceedings of the Ninth International Symposium on Spatial Accuracy Assessment in Natural Resources and Environmental Sciences (Leicester, UK, July 2010), Tate, N.J and P.F. Fisher, Eds., ISARA, pp. 165-168.

Isioye, O.A. and Yang, I.C. (2013). Comparison and validation of ASTER-GDEM and SRTM elevation models over parts of Kaduna State, Nigeria. SASGI Proceedings 2013 - Stream 1.

Iwugo, K.O.; B. D'Arcy; and R. Andoh (2003). Aspects of Land-Based Pollution of an African Coastal Megacity of Lagos. Diffuse Pollution Conference, Dublin 2003. Poster Paper.

Jarvis, A.; H.I. Reuter; A. Nelson; and E. Guevara (2008). Holefilled SRTM for the Globe Version 4, available from the CGIAR-CSI SRTM 90m Database. http://srtm.csi.cgiar.org

Karwel, A.K. and Ewiak, I. (2008). Estimation of the Accuracy of the SRTM Terrain Model on the Area of Poland. The International Archives of the Photogrammetry, Remote Sensing and Spatial Information Sciences. Vol. XXXVII. Part B7. Beijing 2008.

Menegbo, E.M. and Doosu, P. (2015). Vertical Accuracy Assessment of SRTM3 v2.1 and ASTER GDEM v2 using GPS control points for Surveying \& Geoinformatics Applications - Case study of Rivers State, Nigeria. International Journal of Geomatics and Geosciences. 6(1), 81-89.

NASA LP DAAC (2013). NASA Shuttle Radar Topography Mission (SRTM) Version 3.0 (SRTM Plus) Product Release. Land Process Distributed Active Archive Center, National Aeronautics and Space Administration.

NASA/METI. (2011). ASTER GDEM 2 Readme. October 2011.

Nwilo, P.C.; D.N. Olayinka; C.J. Okolie; and E.A. Adzandeh (2012). Transformation of Shuttle Radar Topography Mission (SRTM) Digital Elevation Data to Nigerian Height System. FUTY Journal of the Environment. 7(1), 73-89. http://dx.doi.org/10.4314/fje.v7i1.6.

Patel, A.; S.K. Katiyar; and V. Prasad (2016). Performances Evaluation of different Open source DEM using Differential Global Positioning System (DGPS). The 
Egyptian Journal of Remote Sensing and Space Science, 19(1), 7-16. https://doi.org/10.1016/j.ejrs.2015.12.004

Rexer, M. and Hirt, C. (2014). Comparison of Free High-Resolution Digital Elevation Datasets (ASTER GDEM2, SRTM v2.1/v4.1) and Validation against Accurate Heights from the Australian National Gravity Database; Australian Journal of Earth Sciences, pp. 1-15, doi: 10.1080/08120099.2014.884983, 2014.

Rinehart, R.E. and Coleman, E.J. (1988). Digital Elevation Models produced from Digital Line Graphs. In Proceedings of the ACSM-ASPRS Annual Convention. Volume 2, 291-299. American Congress on Surveying and Mapping, American Society for Photogrammetry and Remote Sensing.

Rodriguez, E. and Martin, J.M. (1992). Theory and Design of Interferometric Synthetic Aperture Radars. IEE Proc.-F. 139(2), 147-159.
Rosen, P.; S. Hensley; I. Li; F. Joughin; S. Madsen; E. Rodriguez; and R. Goldstein (2000). Synthetic Aperture Radar Interferometry - invited paper, Proceedings of the IEEE. 88(3), 333-382.

Temme; A.J.A.M.; G.B.M.; Heuvelink; J.M.; Schoorl; and L. Claessens (2009). Geostatistical Simulation and Error Propagation in Geomorphometry. In T. Hengl, and H.I. Reuter (Eds.), Geomorphometry: Concepts, Software, Applications, (p. 121 - 140) Elsevier (Developments in Soil Science 33) - ISBN 9780123743459.

Zhou, Q. (2017). Digital Elevation Model and Digital Surface Model. In D. Richardson., N. Castree., M.F. Goodchild., A. Kobayashi., W. Liu., and R.A. Marston. (Eds.), The International Encyclopedia of Geography. John Wiley \& Sons, Ltd. doi: 10.1002/9781118786352.wbieg0768 